\title{
INVESTIGATING THE RELATION OF FUNCTIONING AS A DETERMINANT OF WELLBEING TO POLITICAL AND SOCIAL TRUST IN THREE BALKAN COUNTRIES
}

\author{
Anastasia Charalampi ${ }^{1}$, Joanna Tsiganou ${ }^{2}$, Catherine Michalopoulou ${ }^{3}$ \\ e-mail: acharalampi@panteion.gr,e-mail: jtsiganou@ekke.gr, \\ e-mail:kmichal@panteion.gr
}

\begin{abstract}
The measurement of wellbeing, political trust in institutions and social trust provide important indicators of the welfare of nations, political legitimacy and the stability of democratic political systems, and a country's political culture, respectively. In this paper, the relation of functioning as a determinant of wellbeing to political and social trust was investigated using 2012 European Social Survey (ESS) datasets of three Balkan countries: Albania, Bulgaria and Kosovo. This involves first examining the structure of functioning and assess the psychometric properties of the resulting scale (or subscales). Preliminary tests explored the statistically significant relations of functioning to the political and social trust items as well as the socio-demographic variables and the left/right selfplacement scale. Only in the case of the Bulgarian dataset, EFA and CFA resulted in a unidimensional valid and reliable scale measuring functioning scale comprised of all the initial eight items. Although the analysis did not result in the same structure of functioning for the three Balkan countries, it did provide a reliable and valid scale in the cases of Bulgaria and Kosovo. This work could be extended to cover all participating countries of this Round of the ESS.
\end{abstract}

Key words: exploratory factor analysis, confirmatory factor analysis, reliability, validity, European social survey

JEL: C18, I31

\section{Introduction}

The measurement of wellbeing, political trust in institutions and social trust provide important indicators of the welfare of nations, political legitimacy and the stability of democratic political systems, and a country's political culture, respectively. Researchers generally consider wellbeing as a multidimensional concept. In this respect, a module on personal and social wellbeing was introduced

${ }^{1}$ Postdoctoral fellow, PhD, Department of Social Policy, Panteion University of Social and Political Science

${ }^{2} \mathrm{PhD}$, Director of Research, Greek National Center for Social Research-EKKE

${ }^{3}$ Prof., PhD, Department of Social Policy, Panteion University of Social and Political Sciences 
in 2006 (Round 3) and was repeated with certain changes in 2012 (Round 6) of the European Social Survey (ESS). Based on a combination of theoretical models and statistical analyses, the 2012 ESS measurement of personal and social wellbeing (European Social Survey, 2013, 2015; Jeffrey, Abdallah, \& Quick, 2015; New Economics Foundation, 2009) is comprised of 35 items defined in six key dimensions: evaluative wellbeing (two items), emotional wellbeing (six items), functioning (14 items), vitality (four items), community wellbeing (five items) and supportive relationships (four items). Functioning is described by "feelings of autonomy, competence, engagement, meaning and purpose, self-esteem, optimism and resilience" (Jeffrey et al., 2015, p. 4) and Panek (2015) describe positive functioning as comprised of competence, autonomy, engagement, meaning and purpose of life.

The concept of trust has been conceptualized in a rather diverging than converging manner (Bauer, 2014, 2015; Rousseau et al., 1998; Uslaner, 2018) since not all scientists necessarily agree on its meaning (Bacharach \& Gambetta, 2001; Gambetta, 1988; Hardin, 2002; Misztal, 2013; Nooteboom, 2002; Seligman, 2000; Uslaner, 2002; Warren, 1999). In our present study, we limit ourselves to Putnam's (2000) views on social and political trust as aspects of social capital with an emphasis on the dimensions of interpersonal (social) trust and the trust/confidence in political institutions. In the ESS questionnaire five and three items are included for the measurement of political trust in five national institutions (parliament, legal system, police, politicians and political parties) and social trust, respectively.

Research has shown linkages between interpersonal differences in measures of subjective wellbeing to trust in workplace, trust in police, and trust in neighbors, in addition to the standard measure of social trust (Helliwell \& Putnam, 2004). Data suggest benefits from trust in three key aspects of the institutional environment: the legal system, parliament, and politicians (Helliwell, Huang, \& Wang, 2018, p. 426). Research data also offer a potential for making direct comparisons between expected trust and actual trustworthiness (Helliwell et al., 2018). A portion of relevant literature is linking social trust to a range of health outcomes both within and among countries (as reviewed by Kawachi, 2016). In this line research studies are linking social trust to subjective wellbeing (as in Yip, Subramanian, Mitchell, Lee, Wang, \& Kawachi, 2007). Studies have shown that trust and a sense of belonging contribute to subjective wellbeing (Helliwell \& Wang, 2011). A less studied issue on the relation of social trust and wellbeing resides in the resilience that enables high-trust communities to respond more successfully to natural disasters or economic shocks (Yamamura, Tsutsui, Yamane, Yamane, \& Powdthavee, 2015; Uchida, Takahashi, \& Kawahara, 2014). Research has also shown that "the resilience-increasing feature of social trust, which channels its 
benefits especially to those subject to adversity, thereby reduces the inequality of well-being as well as raising its average value" (Helliwell et al., 2018, p. 426). Other studies based on ESS results confirm a strong positive relation between social trust and life evaluations. As argued "these linkages are strong over time within countries as well as between countries. This in turn suggests that social trust, sometimes thought to be culturally fixed, can in fact change within policy-relevant time horizons, and that these changes in social trust are linked to significant changes in national levels of subjective wellbeing" (Helliwell et al., 2018, p. 419).

In this paper, the relation of functioning as a determinant of wellbeing to political and social trust is investigated in three Balkan countries. For the analysis, the 2012 ESS datasets for Albania, Bulgaria and Kosovo are used. First, the structure of the functioning construct consisting of eight common items from both Rounds of the ESS is investigated and its psychometric properties are assessed for each country based on current methodology (Charalampi, 2018; Charalampi, Michalopoulou \& Richardson, 2019, 2020; Michalopoulou, 2017). This involves splitting randomly a sample of adequate size into two halves and first performing Exploratory Factor Analysis (EFA) on one half-sample in order to assess the construct validity of the scale. Secondly, the structure suggested by EFA is validated by carrying out Confirmatory Factor Analysis (CFA) on the second half. Based on the full sample, the psychometric properties of the resulting scales are assessed. Then, the socio-demographic and political "profile" of the functioning scale is examined and statistically significant relations of functioning to the political and social trust items are explored.

\section{Method}

\section{Participants}

The analysis was based on the ESS Round 6 Data (2012) for Albania, Bulgaria and Kosovo. The ESS implements all the strict methodological prerequisites for comparability over time and cross-nationally (Kish, 1994; Carey, 2000) by applying probability sampling, minimum effective achieved sample sizes in all participating countries and a maximum target non-response rate of $30 \%$ (The ESS Sampling Expert Panel, 2016). The standardized questionnaire is designed in British English and then translated by each national team applying the Translation, review, adjudication, presenting and documentation (TRAPD) methodology (Harkness, 2003; Harkness et al., 2010). Face-to-face interviewing is used for data collection.

Applying the same definition to all rounds, the ESS defines the survey population as all individuals aged $15+$ residing within private households in each 
country, regardless of their nationality, citizenship or language. The demographic and social characteristics of the participants are presented in Table 1. As shown, in all samples women were more than men. In the Albanian and Kosovar samples similar characteristics were observed with mean age close to 43 years. More than $62.5 \%$ of the participants were married, more than $84.8 \%$ had completed secondary education or lower and at least $26.1 \%$ were in paid work. In the Bulgarian sample, the mean age was 54 years, $53.4 \%$ of the participants were married, $77.0 \%$ had completed secondary education and $41.5 \%$ were in paid work.

Table 1: Participants' demographic and social characteristics based on the number of cases included in the analysis

\begin{tabular}{|l|c|c|c|c|c|c|c|}
\hline & & Men & Women & Age & Married & $\begin{array}{c}\text { Secondary } \\
\text { education or } \\
\text { lower }\end{array}$ & $\begin{array}{c}\text { In paid } \\
\text { work }\end{array}$ \\
\hline Country & $N$ & $(\%)$ & $(\%)$ & Mean (SD) & $(\%)$ & $(\%)$ & $(\%)$ \\
\hline Albania & 1,201 & 45.7 & 54.3 & $43.8(18.46)$ & 66.8 & 84.8 & 26.1 \\
\hline Bulgaria & 2,260 & 42.4 & 57.6 & $54.0(16.97)$ & 52.4 & 77.0 & 41.5 \\
\hline Kosovo & 1,295 & 47.7 & 52.3 & $43.2(17.09)$ & 62.5 & 86.9 & 26.7 \\
\hline
\end{tabular}

Note. The reference period for the respondent's main activity was defined as during the last 7 days.

Source: European Social Survey (2012).

\section{Instrument}

The structure of the functioning dimension consisting of eight common items from both Rounds is investigated for three Balkan countries of Round 6 (Table 2). The response categories range from 1 to 5 and are defined as follows: 1 (agree strongly); 2 (agree); 3 (neither agree nor disagree); 4 (disagree); 5 (disagree strongly). Therefore, the items' level of measurement is pseudo-interval. The scale is comprised of five positively (F1 and F3-F6) and three negatively (F2, F7 and F8) worded items. The scoring of positively worded items was reversed before the analysis in order to achieve correspondence between the ordering of the response categories. 
Investigating the Relation of Functioning as a Determinant of Wellbeing to Political ...

Table 2: The 2012 European Social Survey (ESS) measurement of functioning

\begin{tabular}{|c|c|c|c|}
\hline Functioning items & $\begin{array}{c}\text { ESS } \\
\text { questionnaire }\end{array}$ & $\begin{array}{c}\text { Aligned } \\
\text { scale }\end{array}$ & $\begin{array}{l}\text { Item } \\
\text { label }\end{array}$ \\
\hline Free to decide how to live my life & D16 & $1-5(\mathrm{R})$ & $\mathrm{F} 1$ \\
\hline Little chance to show how capable I am & D17 & $1-5$ & $\mathrm{~F} 2$ \\
\hline Feel accomplishment from what I do & D18 & $1-5(\mathrm{R})$ & F3 \\
\hline Feel what I do in life is valuable & D23 & $1-5(\mathrm{R})$ & F4 \\
\hline Always optimistic about my future & D2 & $1-5(\mathrm{R})$ & F5 \\
\hline Feel very positive about myself & D3 & $1-5(\mathrm{R})$ & F6 \\
\hline At times I feel as if I am a failure & D4 & $1-5$ & F7 \\
\hline \multicolumn{4}{|c|}{ When things go wrong in my life it takes a long } \\
\hline time to get back to normal & D19 & $1-5$ & $\mathrm{~F} 8$ \\
\hline
\end{tabular}

Source: European Social Survey (2012).

For the measurement of political trust in national institutions (parliament, legal system, police, politicians and political parties), five items are included in the ESS core questionnaire. Each item is assigned a scale ranging from 0 (no trust at all) to 10 (complete trust). Accordingly, for the measurement of social trust, three items are included in the ESS core questionnaire: most people can be trusted (10) or you can't be too careful (0); most people would try to take advantage of me (0)/try to be fair (10); most of the time people try to be helpful (10) or look out for themselves (0). Also, the left/right self-placement scale is used. In the ESS core questionnaire, respondents are asked to place themselves on a scale ranging from 0 (Left) to 10 (Right).

\section{Statistical analyses}

In the first step of the analysis, the sample in each country was randomly split into two halves, following the methodological process of a theory testing case (Thompson, 2005). EFA was performed on the first half in order to assess the construct validity of the scale and then the structured was validated by carrying 
out CFA on the second half. Based on the full sample and the CFA results, the psychometric properties of the scale were assessed. Statistical analyses were performed using the Mplus Version 8.6 and the IBM SPSS Statistics Version 20.

Sample sizes of Albania, Bulgaria and Kosovo were 1,201, 2,260 and 1,295 cases, respectively. Therefore, the samples were considered large enough $(>300)$ for carrying out factor analyses separately in each country (Tabachnick \& Fidell, 2007).

Initially, missing data analysis and data screening for outliers and unengaged responses was performed for both half-samples. Only cases with missing values on all items were excluded automatically from the analysis (Muthén \& Muthén, 1998 - 2017). In addition, cases were eliminated if they exhibited low standard deviation $(<0.5)$, i.e. no variance in the responses. Data screening for outliers was based on background variables e.g., gender (dichotomy), age (ratio) and education (pseudo-interval). Cases were eliminated if they were shown in the boxplots as outliers (Brown, 2015; Tabachnick \& Fidell, 2007; Thompson, 2005).

In performing EFA, the following sequence of decisions was required:

1. Initially, the items' frequency distributions were inspected for floor and ceiling effects, bearing in mind that the percentages of responses less than 15 are normally deemed acceptable (Terwee et al., 2007). The appropriate univariate statistics were computed for each item and their distributional properties were inspected (testing for normality) to decide on the appropriateness of the methods to be used. The criterion of corrected itemtotal correlations $<.30$ (Nunnally \& Bernstein, 1994) was used to decide which items to exclude from the analysis.

2. The covariance matrix was employed as the appropriate matrix of associations (Brown, 2015).

3. Maximum likelihood was applied as the appropriate method of factor extraction (Brown, 2015).

4. Geomin rotation was used as the appropriate oblique factor rotation method (Brown, 2015)

5. Considering the factor analytic theory, "factors that are represented by two or three indicators may be underdetermined [...] and highly unstable across replications" (Brown, 2015, p. 21), only one to two factors could be tested for each country.

6. Items were considered salient if their factor loadings were $>.30$ and therefore the meaning of the dimension was inferred from these items (Fabrigar et al., 1999; Thompson, 2005). Items with loadings $>.30$ on one factor and $>.22$ on another factor were considered as "cross-loading" items 
Investigating the Relation of Functioning as a Determinant of Wellbeing to Political ...

(Stevens, 2002). Items with loadings $<.30$ (i.e., low communalities) were excluded from the analysis (Brown, 2015).

In performing CFA, the following sequence of decisions was required:

1. The decision on the inclusion of items in the analysis was based on the results of the item analysis and EFA carried out on the first half-sample.

2. CFA was performed using the covariance matrix of associations and maximum likelihood estimation.

3. The model fit was considered adequate if $\chi^{2} / d f<3$, the standardized rootmean-square residual $(\mathrm{SRMR})<.05$, the comparative fit index $(\mathrm{CFI})$ and Tucker-Lewis index (TLI) values were greater than or close to .95 and the root-mean-square error approximation (RMSEA) $\leq .06$ with the $90 \%$ confidence interval (CI) upper limit $\leq .06$ (Bollen, 1989; Brown, 2015; Hu \& Bentler, 1999; Schmitt, 2011; Tabachnick \& Fidell, 2007; Thompson, 2005). The model fit was considered acceptable if $\chi^{2} / d f<3$, SRMR $<.08$, the CFI and TLI values were $>.90$ and the RMSEA $<.08$ with the $90 \% \mathrm{CI}$ upper limit $<.08$ (Hu \& Bentler, 1999; Marsh, Hau \& Wan, 2004).

4. Searches for modification indices and further specifications were performed. Where necessary, correlations between error variances were introduced (Brown, 2015; Thompson, 2005).

The functioning scale was constructed for the full sample of all three countries by averaging the defining items so that low and high scores would indicate low and high levels of functioning and descriptive statistics were computed. Based on the CFA results for the full sample, the average variance extracted (AVE) was computed for each scale. Convergent validity was considered adequate if the AVE was above or around .50 (Fornell \& Larcker, 1981). The average interitem correlations in the recommended range of .15-.5 that cluster near their mean value were used as an indication of the unidimensionality of the scale (Clark \& Watson, 1995). Evidence of discriminant validity was considered adequate if the squared correlations between subscales were less than their AVE estimates (Fornell \& Larcker, 1981). Moreover, based on the CFA results for the full sample, a scale was considered reliable if the composite reliability coefficient (Raykov, 2007) was above or around .70, i.e. using the same Nunnally and Bernstein (1994) criterion as for Cronbach's alpha coefficients. However, if AVE is less than 0.5 , but composite reliability is higher than 0.6 , the convergent validity of the construct is still adequate (Fornell \& Larcker, 1981).

In order to obtain a more meaningful representation of the respondents' scores and for better interpretation, $\mathrm{k}$-means clustering $(\mathrm{k}=5)$ was performed in order to transform the raw scores into a 1-5 scale (Michalopoulou \& Symenonaki, 2017). Cross-tabulations between the subscales' raw scores and the resulting clusters were performed so as to indicate the cut-off points for recoding the subscale scores. 
Cross-tabulations and chi-square tests were performed in order to obtain the functioning scale's socio-demographic "profile" and investigate its association to the political trust and social trust items and the left/right self-placement scale. Statistical significance at $p<0.05$ was used as a criterion for presenting the results.

\section{Results}

The full sample screening of the datasets identified no unengaged responses (standard deviation $=.000$ ) and no outlying cases. Three, five and four cases in the Albanian, Bulgarian and Kosovar samples, respectively, were rejected from the analysis because of missing values on all items.

\section{The construct of (positive) functioning: $E F A$ and $C F A$ results}

In every country of the ESS datasets, respondents had used the full range of possible responses for all functioning items (Table 3). The majority of the responses were clustered closer to the higher end of their respective scales. Strong ceiling effects were detected for four items (F1, F4, F5 and F6) in the Albanian and Kosovar samples. The lowest mean responses were detected for two items (F2 and F8) in all three datasets. Based on the criterion of corrected item-total correlations $<.30$, four (F2, F4, F7 and F8) and three (F2, F7 and F8) items of the Albania and Kosovar samples, respectively, were rejected from further analysis. Only in the case of the Bulgarian dataset, the analysis proceeded with all the initial eight items. Non-normality was not severe for any item (skewness $>2$; kurtosis $>7$ ). As shown, the proportion of missing values was negligible exceeding $3.5 \%$ only for two items of the Kosovar sample (F7 and F8).

EFA was performed on the first half-samples with the maximum likelihood of the covariance matrix of associations resulting in a unidimensional solution. Table 4 shows the factorial structure of the one-factor solutions. All items exhibited strong factor loadings ( $\geq .40$ ) with the exception of one item (F2) in the Bulgarian sample. 
Investigating the Relation of Functioning as a Determinant of Wellbeing to Political ...

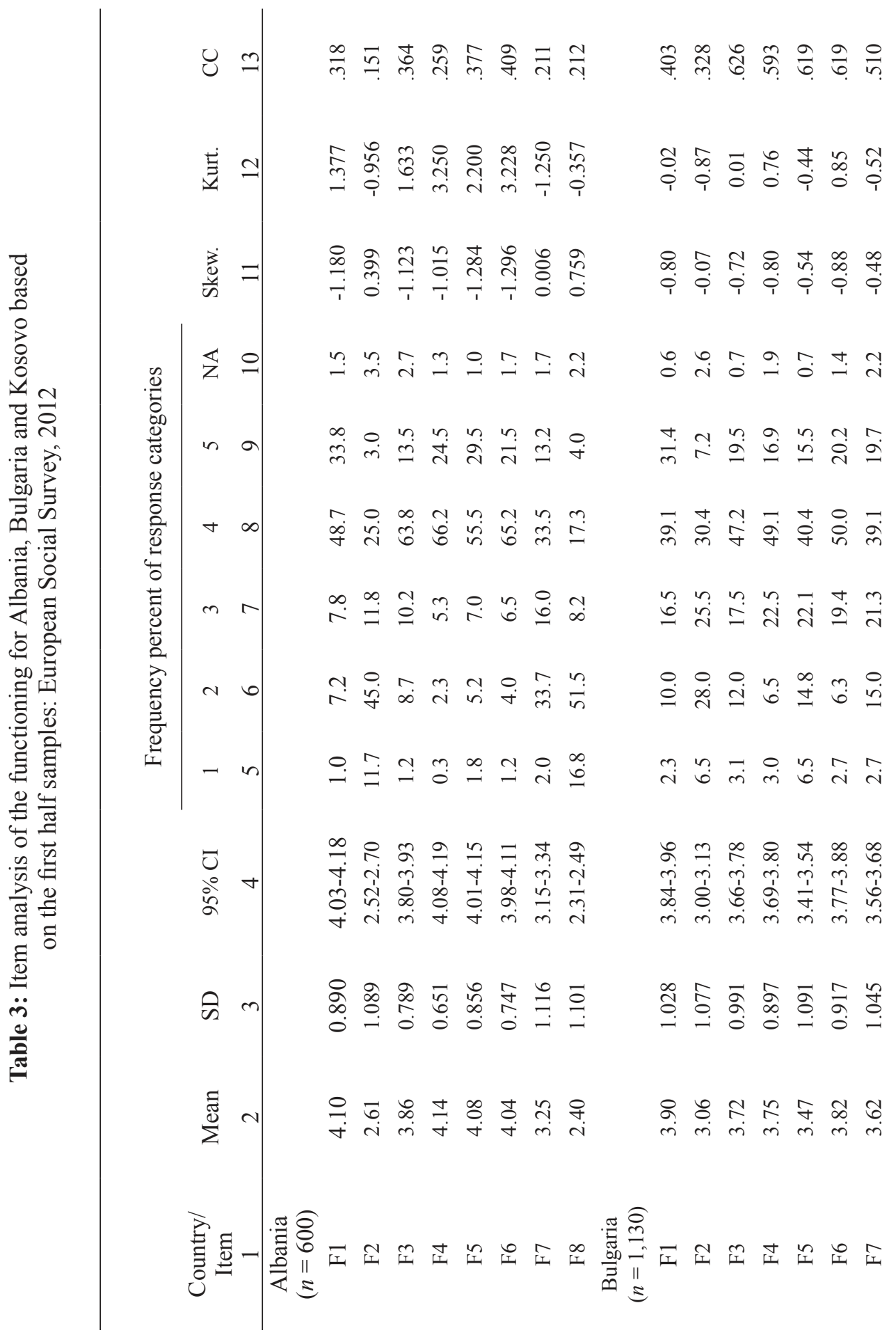




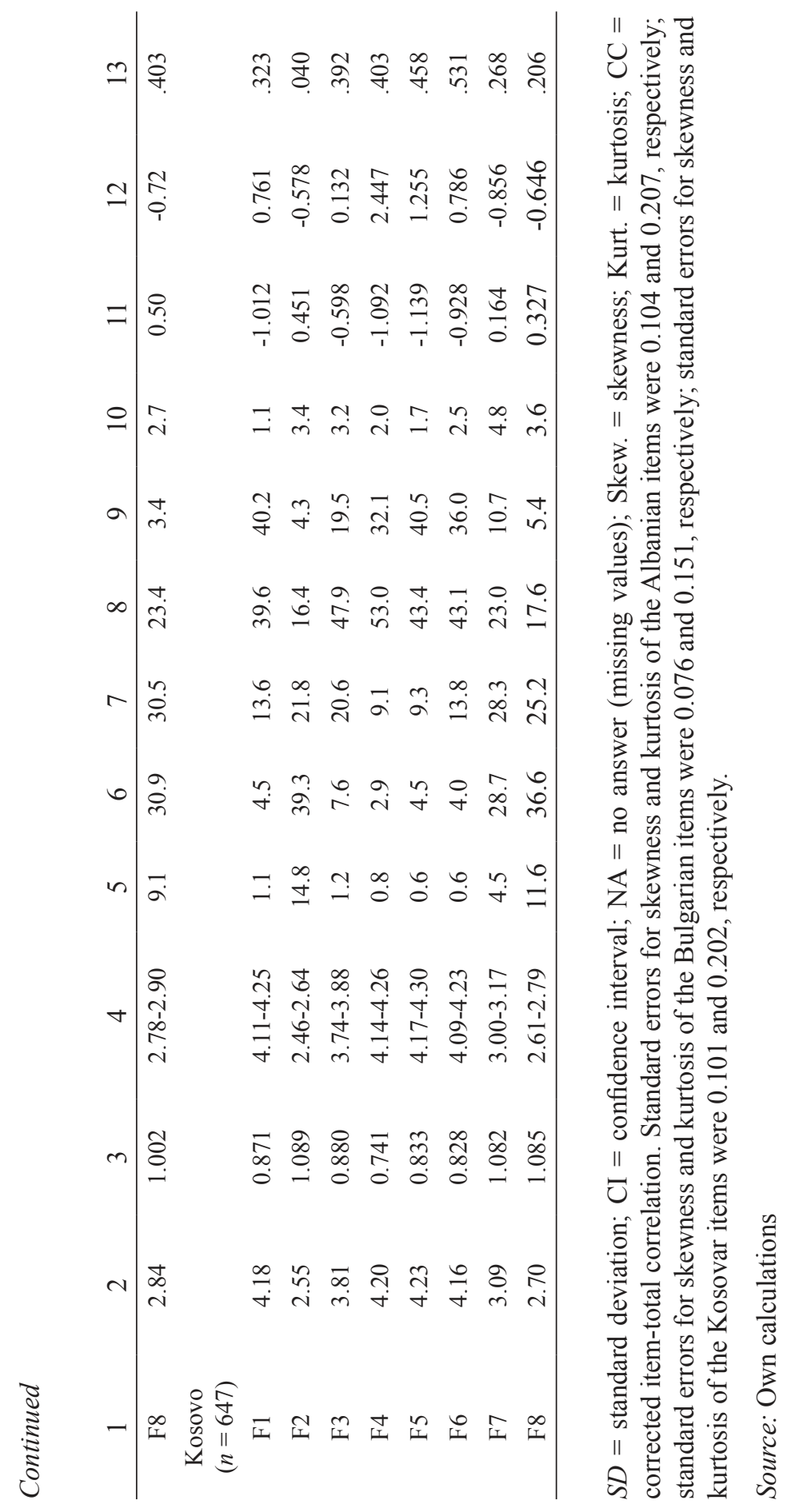


Investigating the Relation of Functioning as a Determinant of Wellbeing to Political ...

Table 4: Exploratory factor analysis of the 2012 European Social Survey Functioning scale performed with maximum likelihood of the covariance matrix on the first half-sample of each country: Factor loadings of the one-factor model

\begin{tabular}{lccccccccc}
\hline Country & $\boldsymbol{n}$ & F1 & F2 & F3 & F4 & F5 & F6 & F7 & F8 \\
\hline Albania & 599 & .512 & - & .439 & - & .627 & .736 & - & - \\
Bulgaria & 1,129 & .476 & .346 & .710 & .704 & .747 & .749 & .587 & .427 \\
Kosovo & 646 & .494 & - & .530 & .515 & .752 & .827 & - & - \\
\hline
\end{tabular}

Source: Based on Social Survey (2012).

The one first-order factor model indicated by the EFA results was tested by performing CFA on the second half-samples. Modification searches were conducted and, where necessary, correlations between error variances were introduced. The CFA results (Figure 1) for the Albanian sample were $\chi 2 / \mathrm{df}=$ 5.98, $\mathrm{SRMR}=.030, \mathrm{CFI}=.961, \mathrm{TLI}=.882, \mathrm{RMSEA}(90 \% \mathrm{CI})=.091(.046-.144)$ suggesting an inadequate model fit. The CFA results for the Bulgarian sample were $\chi 2 / \mathrm{df}=2.88, \mathrm{SRMR}=.021, \mathrm{CFI}=.987, \mathrm{TLI}=.980, \mathrm{RMSEA}(90 \% \mathrm{CI})=$ .041 (.028-.054) suggesting an adequate model fit. Bearing in mind that RMSEA tends to improve whereas the CFI and TLI tend to worsen as the number of items in the model increases (Kenny \& McCoach, 2003) and relying on the SRMR, CFI and TLI values, the Kosovar model $(\chi 2 / \mathrm{df}=0.69, \mathrm{SRMR}=.010, \mathrm{CFI}=1.000$, $\mathrm{TLI}=1.000$, RMSEA $=.000$ with the $90 \% \mathrm{CI}=.000-.050)$ provided an almost perfect model fit. 


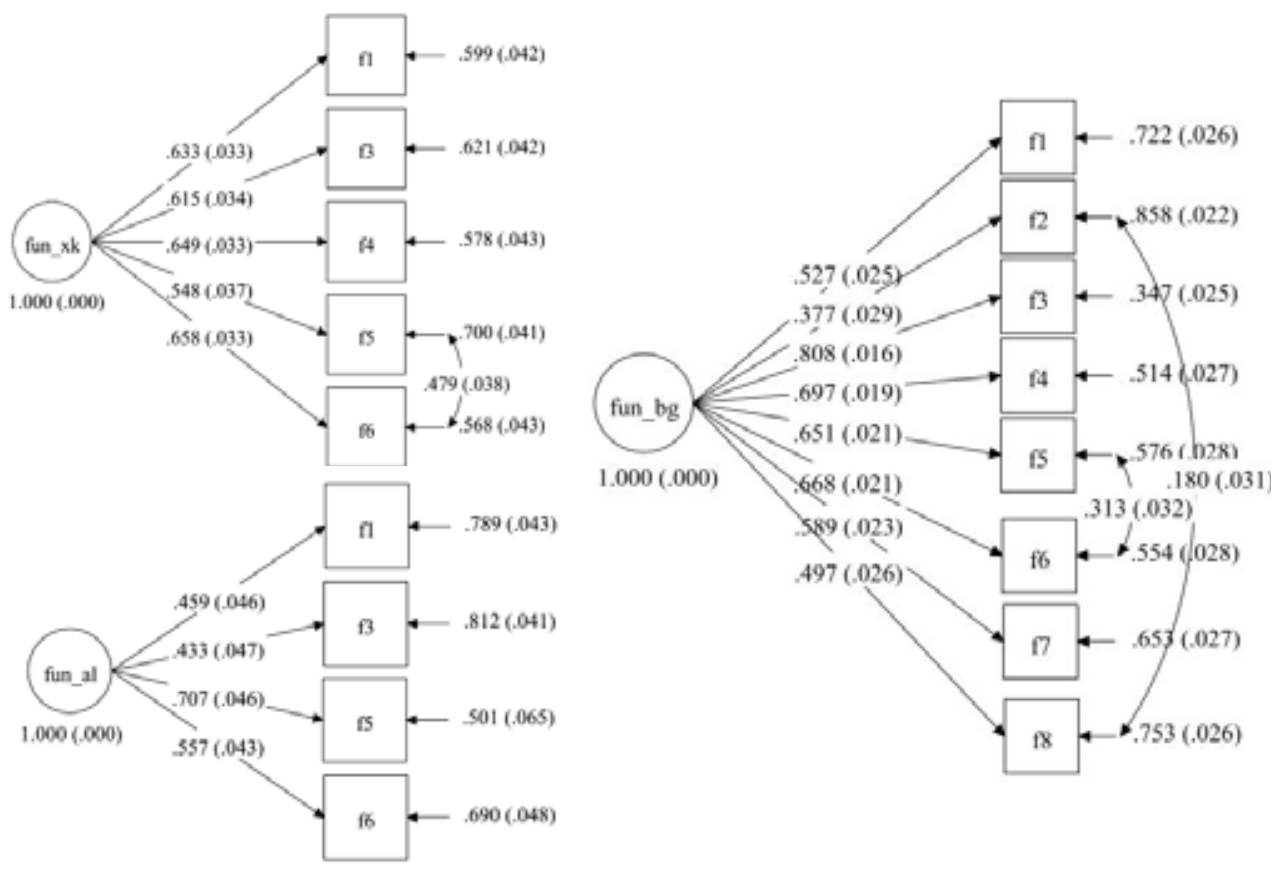

Source: Based on Social Survey (2012).

Figure 1: Standardized solution for the model with one first-order factor based on CFA analysis performed on the second half-samples of Albania $(n=599)$, Bulgaria $(n=1,126)$ and Kosovo $(n=645)$. Observed variables are represented by squares and the latent variable by a circle.

\section{Psychometric properties of the (positive) functioning scale}

Scales were constructed by averaging their defining items. In Table 5, descriptive statistics, the convergent validity and composite reliability are presented for the three countries. CFA analysis repeated for the full samples (Figure 2) of Bulgaria $\left(\chi^{2} / d f=3.52, \mathrm{SRMR}=.015, \mathrm{CFI}=.993, \mathrm{TLI}=.986\right.$ and $\mathrm{RMSEA}=.033$ with the $90 \% \mathrm{CI}=.024-.043)$ provided an adequate model fit. Based on the argument presented for the half-samples CFA results, the Albanian $\left(\chi^{2} / d f=0.33\right.$, $\mathrm{SRMR}=.003, \mathrm{CFI}=1.000, \mathrm{TLI}=1.000$ and $\mathrm{RMSEA}=.000$ with the $90 \% \mathrm{CI}=$ $.000-.063)$ and the Kosovar models $\left(\chi^{2} / d f=0.58, \mathrm{SRMR}=.006, \mathrm{CFI}=1.000\right.$, TLI $=1.000$ and $\mathrm{RMSEA}=.000$ with the $90 \% \mathrm{CI}=.000-.032)$ provided an almost perfect model fit. 

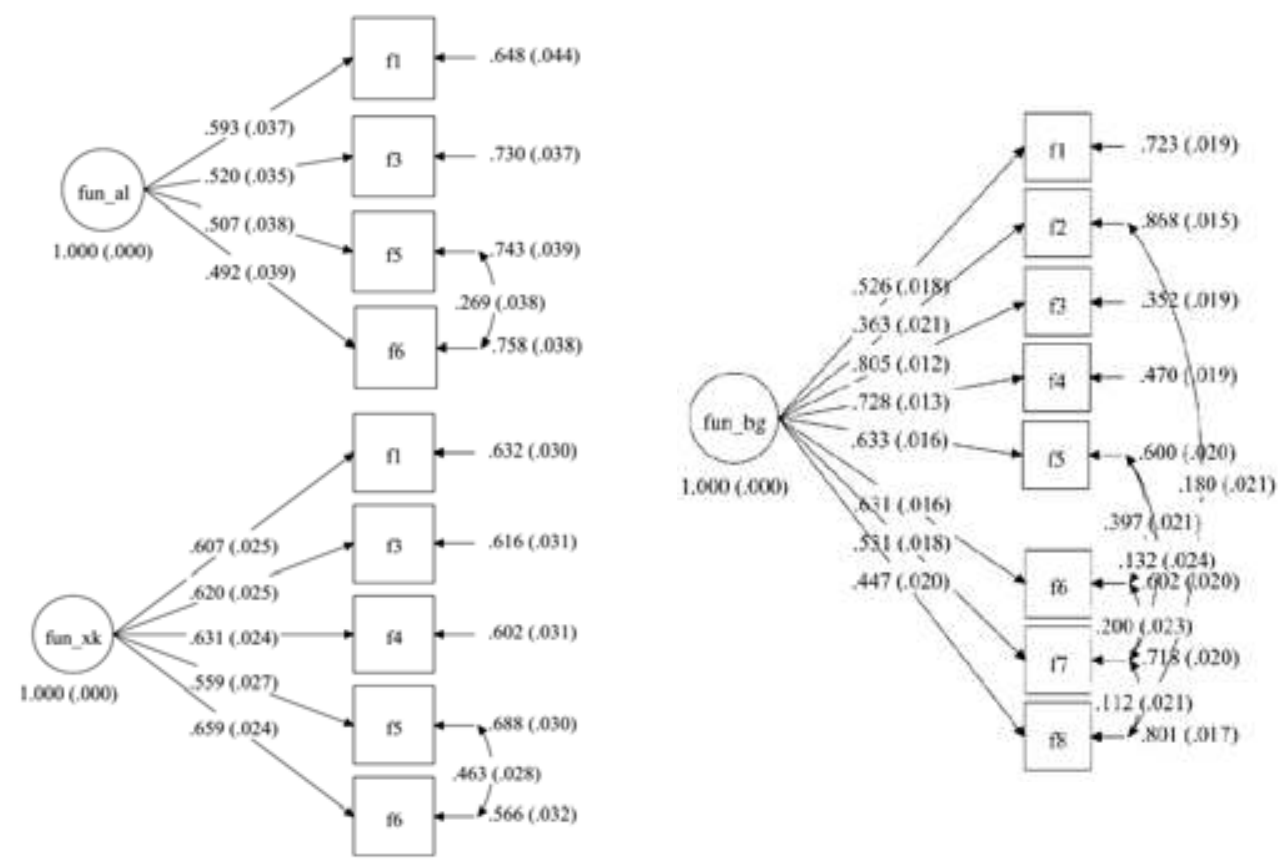

Source: Based on Social Survey (2012).

Figure 2: Standardized solution for the model with one first-order factor based on CFA analysis performed on the full samples of Albania $(N=1,198)$, Bulgaria $(N=2,255)$

and Kosovo $(N=1,291)$. Observed variables are represented by squares and the latent variable by a circle.

The AVE of the (positive) functioning scale was below the 0.5 limit in all cases (Table 5). However, composite reliability was higher than 0.6 providing therefore evidence of adequate convergent validity. The average inter-item correlations were within the recommended range for unidimensionality (.15$.5)$ in all countries. In the Bulgarian and Kosovar samples, the (positive) functioning scale was reliable with composite reliability values .809 and .753 ( $\geq .70$ ), respectively. However, in the Albanian sample, composite reliability value was less than the necessary limit.

\section{Socio-demographic "profile" of the functioning scale}

In the case of the Bulgarian sample (Figure 3), 9.7\% of men scored higher on the higher end of the functioning scale (5) as compared to $5.6 \%$ of the women. Younger participants scored higher on the higher end of the scale than older 
ones: 18-24 (8.0\%); 25-34 (14.2\%); 35-44 (7.9\%); 45-54 (8.8\%); 55-64 (6.7\%); $65+(4.6 \%)$. Moreover, $9.7 \%$ of the unmarried participants scored higher on the higher end of the scale (5) as compared to the $8.0 \%$ of the married ones. Those with a higher level of educational attainment scored higher on the higher end of the scale (5) than those having less than lower secondary education: tertiary (11.8\%); upper secondary (7.1\%); lower secondary (6.5\%); less than lower secondary (1.8\%). In accordance with the employment status, $12.0 \%$ and $4.5 \%$ of the employed and unemployed, respectively, scored higher on the higher end of the scale (5) as compared to the $3.9 \%$ of the inactive.

Table 5: Descriptive statistics, convergent validity, composite and internal consistencies of the Functioning scale based on the full sample of each country:

European Social Survey, 2012

\begin{tabular}{|c|c|c|c|}
\hline & \multicolumn{3}{|c|}{ Unidimensional scale* } \\
\hline & $\begin{array}{c}\text { Albania } \\
(N=1,198)\end{array}$ & $\begin{array}{c}\text { Bulgaria } \\
(N=2,255)\end{array}$ & $\begin{array}{c}\text { Kosovo } \\
(N=\mathbf{1 , 2 9 1})\end{array}$ \\
\hline Number of items & 4 & 8 & 5 \\
\hline Mean (standard error) & $3.99(0.017)$ & $3.26(0.020)$ & $4.11(0.017)$ \\
\hline $95 \%$ Confidence interval & $3.96-4.02$ & $3.22-3.30$ & $4.07-4.14$ \\
\hline Standard deviation & 0.577 & 0.925 & 0.598 \\
\hline Skewness (standard error) & $-1.016(0.072)$ & $-0.199(0.054)$ & $-0.721(0.070)$ \\
\hline Kurtosis (standard error) & $2.200(0.144)$ & $-0.272(0.108)$ & $0.663(0.140)$ \\
\hline Convergent validity & .280 & .358 & .380 \\
\hline Composite reliability & .608 & .809 & .753 \\
\hline Average inter-item correl. & .309 & .348 & .397 \\
\hline Min.-max. correlations & $.247-.449$ & $.159-.629$ & $.303-.654$ \\
\hline Range of correlations & .201 & .470 & .350 \\
\hline
\end{tabular}

* The four and five items (Albania and Kosovo, respectively) of the scale are measuring positive functioning and the eight (Bulgaria) items of the scale are measuring positive functioning.

Source: own calculations

In the case of the Kosovar sample (Figure 3), 28.3\% of men scored higher on the higher end of the positive functioning scale (5) as compared to $27.5 \%$ of women. Younger participants scored higher on the higher end of the scale than older ones: 18-24 (39.7\%); 25-34 (30.4\%); 35-44 (28.7\%); 45-54 (27.1\%); 55-64 (20.5\%); 65+(13.7\%). In accordance with marital status, $35.0 \%$ of the unmarried participants scored higher on the higher end of the scale (5) as compared to the $26.0 \%$ of the married ones. Those with higher level of educational attainment 
Investigating the Relation of Functioning as a Determinant of Wellbeing to Political ...

scored higher on the higher end of the scale (5) than those having less than lower secondary education: tertiary $(40.3 \%)$; upper secondary $(30.6 \%)$; lower secondary $(28.1 \%)$; less than lower secondary (15.6\%). In addition, $35.2 \%$ and $25.7 \%$ of the employed and inactive, respectively, scored higher on the higher end of the scale (5) as compared to the $24.4 \%$ of the unemployed.

Functioning: ESS, Bulgaria

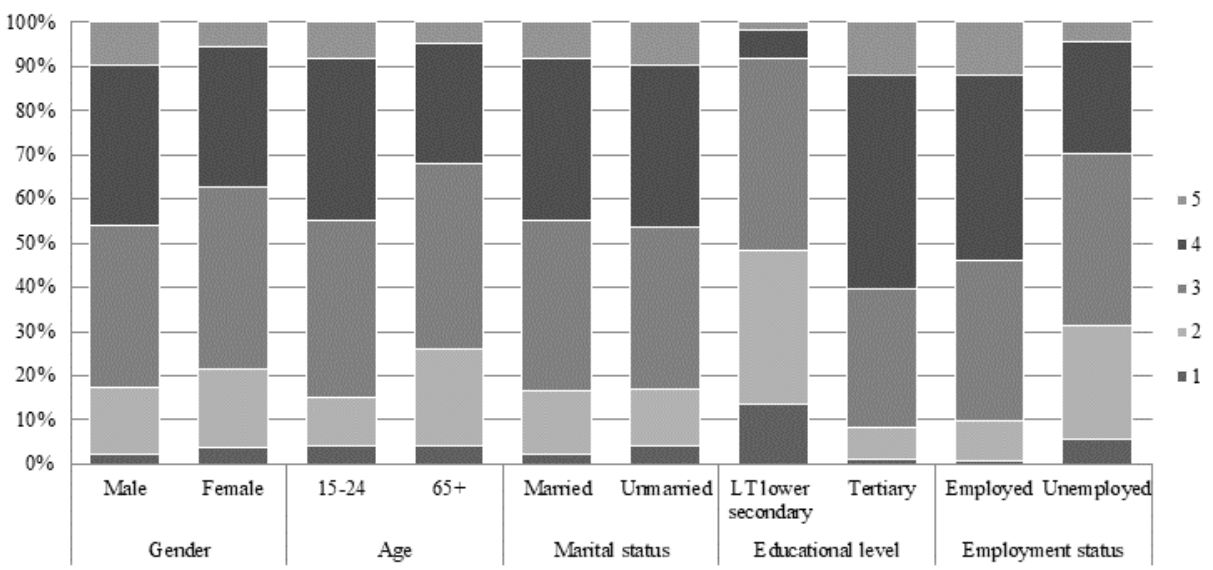

Positive Functioning: ESS, Kosovo

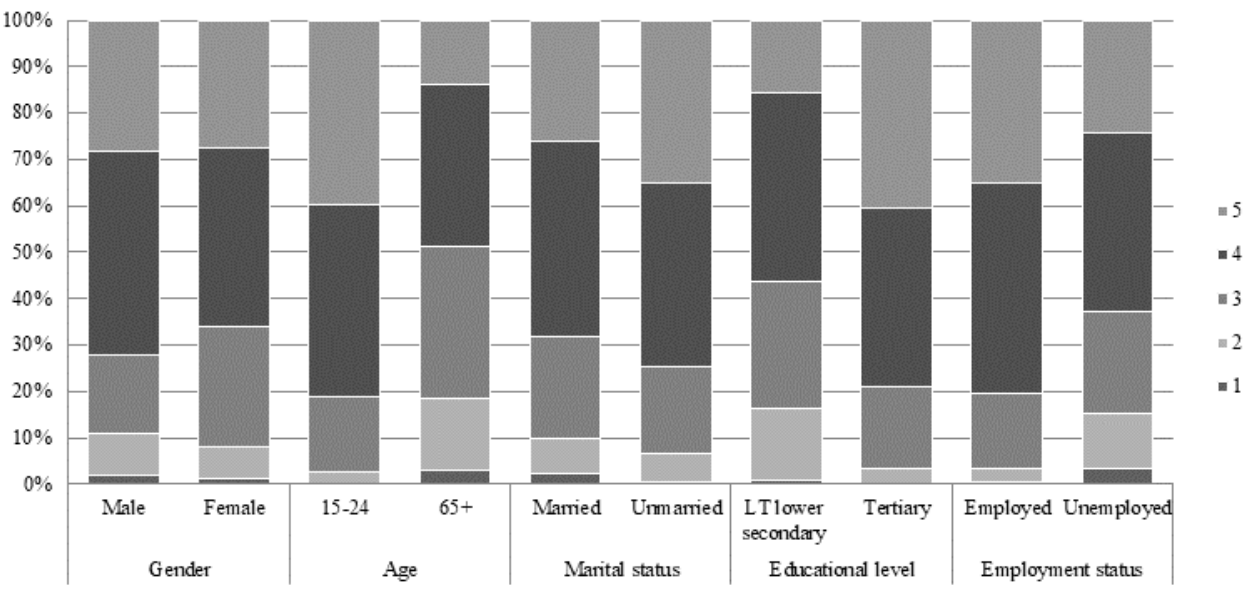

Source: Based on Social Survey (2012).

Figure 3: The demographic and social "profile" of the (positive) functioning scale for Bulgaria and Kosovo: European Social Survey, 2012 


\section{Political and social "profile" of the (positive) functioning scale: Mean scores comparisons}

In the Bulgarian sample (Figure 4), lower levels (5) of functioning were obtained for trust in the parliament, the legal system, the police, the politicians and the political parties with mean scores 4.00, 3.25, 3.40, 3.56 and 3.70, respectively, as compared to the higher (1) levels of functioning (mean scores 3.14, 3.14, 3.05, 3.16 and 3.14). In the Kosovar sample (Figure 4), lower levels (5) of positive functioning were obtained for trust in the legal system and the police with mean scores 4.21 and 4.19, respectively, as compared to the higher (1) levels of positive functioning (mean scores 3.82 and 3.81).

Functioning: ESS, Bulgaria

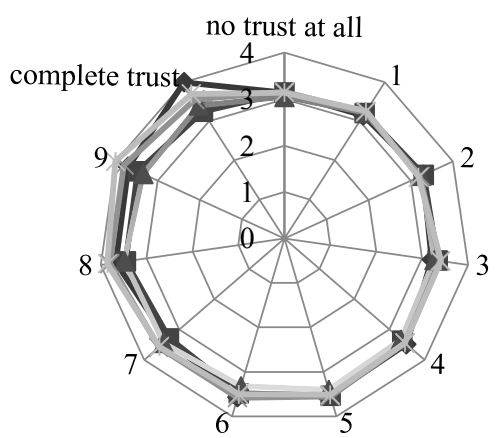

$$
\begin{aligned}
& \longrightarrow \text { country's parliament } \\
& \longleftarrow \text { legal system } \\
& \longleftarrow \text { police } \\
& \approx \text { politicians } \\
& \approx \text { political parties }
\end{aligned}
$$

\section{Positive Functioning: ESS, Kosovo}

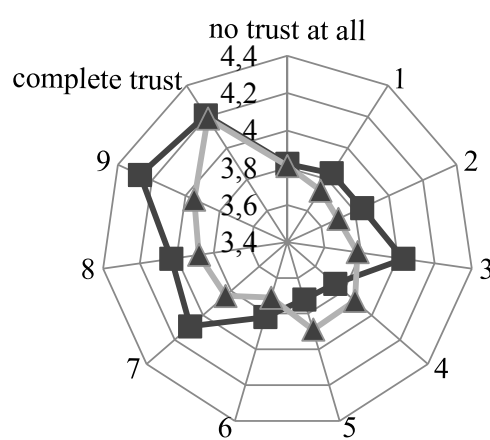

$\rightarrow$ legal system $\triangle$ - police

Source: Based on Social Survey (2012).

Figure 4: The mean scores of the (positive) functioning scale on political trust in national institutions for Bulgaria and Kosovo

In the Bulgarian sample (Figure 5), lower levels (5) of functioning were obtained for the three social trust items ("most people can be trusted or you can't be too careful", "most people would try to take advantage of me/try to be fair", "most of the time people try to be helpful or look out for themselves") with mean scores 3.62, 3.56, and 3.36, respectively, as compared to the higher (1) levels of functioning (mean scores 3.21, 3.04 and 3.04). In the Kosovar sample (Figure 5), lower levels (5) of positive functioning were obtained for the one of the social trust items ("most people would try to take advantage of me/try to be fair") with 
a mean score 4.24 as compared to the higher (1) levels of positive functioning (mean scores 3.98). The reverse holds true for the second social trust item ("most people would try to take advantage of me/ try to be fair").

Functioning: ESS, Bulgaria

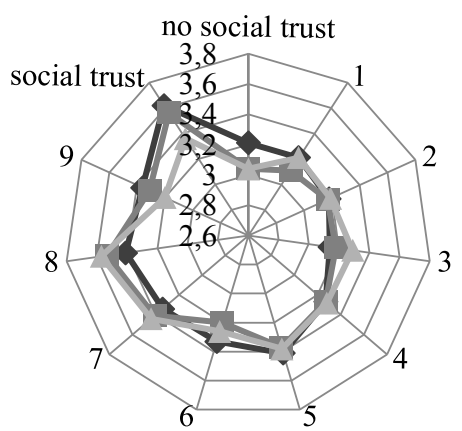

$\longrightarrow$ most people can be trusted (10) or you can't be too careful (0)

- most people would try to take advantage of me (0) or try to be fair (10)

$\longrightarrow$ most of the time people try to be helpful (10) or look out for themselves (0)

\section{Positive Functioning: ESS, Kosovo}

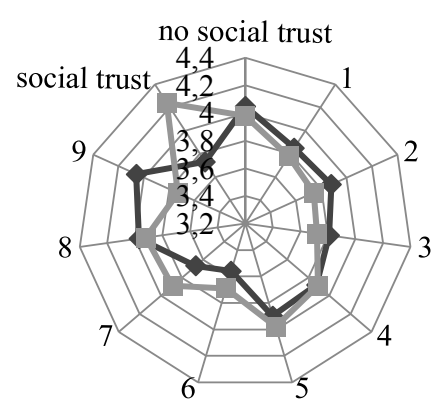
$\longrightarrow$ most people can be trusted (10) or you can't be too careful (0)
$\longrightarrow$ most people would try to take advantage of me $(0)$ or try to be fair (10)

Source: Based on Social Survey (2012).

Figure 5: The mean scores of the (positive) functioning scale measurement of social trust for Bulgaria and Kosovo

In the Bulgarian sample (Figure 6), lower levels of functioning (mean score 3.63) were detected for those inclined to the right end (10) of the left/right selfplacement scale as compared to those on the left (0) end (mean score 3.01). In the Kosovar sample (Figure 6), lower levels of functioning (mean score 4.24) were detected for those inclined to the left end (0) of the left/right self-placement scale as compare to those on the right (0) end (mean score 4.17). 

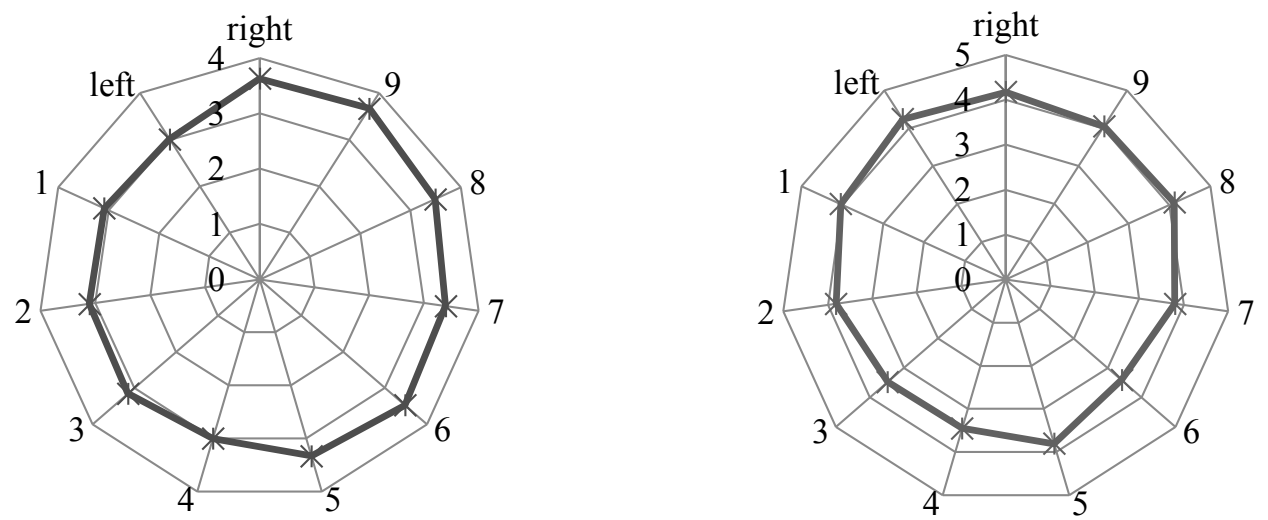

Source: Based on Social Survey (2012).

Figure 6: The mean scores of the (positive) functioning scale on the left/right self-placement scale for Bulgaria and Kosovo

\section{Conclusions}

This study investigated the relation of functioning as a determinant of wellbeing to political and social trust in three Balkan countries based on the 2012 ESS datasets for Albania, Bulgaria and Kosovo.

The investigation of the structure (dimensionality) of the 2012 measurement of functioning by applying the traditional approaches of EFA and CFA to randomly split half-samples resulted in all countries in a unidimensional structure consisting of different items in each case. Only in the case of the Bulgarian dataset the functioning scale comprised by all the initial eight items as four and three in the Albanian and Kosovar samples, respectively, were rejected based on the criterion of corrected item-total correlations $<.30$. The CFA results of the second half samples suggested an inadequate, an adequate and an almost perfect fit for a unidimensional solution measuring (positive) functioning for Albania, Bulgaria and Kosovo, respectively. The relevant CFA results of the full samples suggested an adequate model fit for the functioning scale of Bulgaria and an almost perfect fit for the (positive) functioning scale of Albania and Kosovo. The analysis provided reliable and valid scales of (positive) functioning for Bulgaria and Kosovo. 
The analysis of the functioning scale's socio-demographic "profile" in the case of the Bulgarian sample resulted in younger men participants, unmarried with a higher level of educational attainment and economically active (employed and unemployed) having lower levels of functioning. The analysis of the positive functioning scale's socio-demographic "profile" in the case of the Kosovar sample resulted in younger men participants, unmarried, employed with higher level of educational attainment having lower levels of functioning.

In the Bulgarian dataset, the mean scores of functioning increased as the levels of political and social trust were getting higher and moving closer to the selfplacement scale's right end. In the Kosovar dataset, the mean scores of positive functioning increased as the levels of political and social trust were getting higher and moving closer to the self-placement scale's left end. Although these findings are not comparable between countries, the difference in the direction of these trends should be noted. However, we are not in a position to provide a sound interpretation based on our data analyses and we may hypothesize only that they are due to the specific socio-political, cultural and historical circumstances prevalent in each country, an issue that is excluded from the scope of the present study.

All in all, although the analysis did not result in the same structure of functioning for the three Balkan countries, it did provide a reliable and valid scale for Bulgaria and Kosovo. Because of the different structures, the sociodemographic and political "profiles" are not comparable. Further analysis is necessary to render them comparable and cover all participating countries of this Round of the ESS. Moreover, our analysis has indicated a strong positive relation between trust and the - less studied - functioning as an aspect of wellbeing. To this respect it has offered a base for the verification of the hypothesis that the linkage between trust and well-being is both culturally fixed but also prone to change, as changes in the levels of trust seem to lead to "changes in national levels of subjective well-being" (Helliwell et al., 2018, p. 419).

\section{Sponsorship}

This work was supported by the regional conference "Trust and well-being in the Balkans", held on 30 September - 1 October, organized by the Bulgarian Sociological Association in collaboration with the national sociological associations of Romania, Serbia and Northern Macedonia, and with the financial support of the International Sociological Association. 


\section{References}

Bacharach, M. \& Gambetta, D. (2001). Trust in signs, in Cook, K. S. (Ed.), Trust in Society, New York: Russell Sage Foundation, pp. 148-184.

Bartholomew, D. J., Steele, F., Moustaki I. \& Galbraith, J. (2008). Analysis of multivariate social science data, London: Chapman \& Hall/CRC.

Bauer, P. C. (2014). Conceptualizing Trust and Trustworthiness. Working paper published in Political Concepts Working Paper Series, 61, available at SSRN: http://dx.doi.org/10.2139/ssrn.2325989

Bauer, P. C. (2015). Three Essays on the Concept of Trust and Its Foundations, Bern: University of Bern.

Bollen, K. A. (1989). Structural equations with latent variables, New York: Wiley.

Brown, T. A. (2015). Confirmatory factor analysis for applied research (2nd edition), New York: The Guildford Press.

Carey, S. (Ed.) (2000). Measuring adult literacy: The International Adult Literacy Survey (IALS) in the European context, London: Office for National Statistics.

Charalampi, A. (2018). The importance of items' level of measurement in investigating the structure and assessing the psychometric properties of multidimensional constructs (Doctoral dissertation), Athens: Panteion University of Social and Political Sciences.

Charalampi, A., Michalopoulou C. \& Richardson C. (2019). Determining the structure and assessing the psychometric properties of multidimensional scales constructed from ordinal and pseudo-interval items, Communications in Statistics - Case Studies, Data Analysis and Applications, 5(1), pp. 26-38, doi: 10.1080/23737484.2019.1579683

Charalampi, A., Michalopoulou, C. \& Richardson, C. (2020). Validation of the 2012 European Social Survey measurement of wellbeing in seventeen European countries, Applied Research in Quality of Life, 15(1), pp. 73-105. doi: $10.1007 / \mathrm{s} 11482-018-9666-4$

Clark, L. A. \& Watson, D. (1995). Constructing validity: Basic issues in objective scale development, Psychological Assessment, 7(3), pp. 309-319.

European Social Survey. (2013). Round 6 module on personal and social wellbeing - Final module in template, London: Centre for Comparative Social Surveys, City University London.

European Social Survey. (2015). Measuring and reporting on Europeans' wellbeing: Findings from the European Social Survey, London: ESS ERIC, available at: https://www.europeansocialsurvey.org/docs/findings/ESS1-6_measuring and_reporting_europeans_wellbeing.pdf (accessed 30 May 2016)

European Social Survey. (2012). Round 6 Data. Data file edition 2.4, NSD - Norwegian Centre for Research Data, Norway - Data Archive and distributor of ESS data for ESS ERIC. 
Investigating the Relation of Functioning as a Determinant of Wellbeing to Political ...

Fabrigar, L. R., Wegener, D. T., MacCallum R. C. \& Strahan E. J. (1999). Evaluating the use of exploratory factor analysis in psychological research, Psychological Methods, 4(3), pp. 272-299.

Fornell, C. \& Larcker, D. F. (1981). Evaluating structural equation models with unobservable variables and measurement error, Journal of Marketing Research, 18(1), pp. 39-50.

Gambetta, D. (1988). Can we trust trust?, in Gambetta, D. (Ed.), Trust: Making and Breaking Cooperative Relations, Cambridge: Basil Blackwell, pp. 213-237.

Hardin, R. (2002). Trust and Trustworthiness, New York: Russell Sage Foundation.

Harkness, J. A. (2003). Questionnaire translation, in Harkness, J. A, Van de Vijver, F. J. R., \& Mohler, P. P. (Eds.), Cross-cultural survey methodology, Hoboken, NJ: Wiley, pp. 35-56.

Harkness, J. A., Villar, A., \& Edwards, B. (2010). Translation, adaptation and design, in Harkness, J. A., Braun, M., Edwards, B., Johnson, T. P., Lyberg, L., Mohler, P. P., Pennell, B. E. \& Smith T. W. (Eds), Survey methods in multinational, multiregional, and multicultural contexts, Hoboken, NJ: Wiley, pp. 117-140.

Helliwell, J. F., Huang, H., \& Wang, S. (2018). New evidence on trust and wellbeing, in Uslaner, E. M. (Ed.), The Oxford handbook of social and political trust, Oxford, UK: Oxford University Press, pp. 409-446.

Helliwell, J. F. \& Putnam, R. D. (2004). The social context of well-being, Philosophical Transactions-Royal Society of London Series B Biological Sciences, 359(1449), pp. 1435-1446.

Helliwell, J. F., \& Wang, S. (2011). Trust and well-being, International Journal of Wellbeing, 1(1), pp. 42-78.

Hu, L. \& Bentler P. M. (1999). Cutoff criteria for fit indexes in covariance structure analysis: Conventional criteria versus new alternatives, Structural Equation Modeling, 6(1), pp. 1-55.

Jeffrey, K., Abdallah, S., \& Quick, A. (2015). Europeans' personal and social wellbeing: Topline results from Round 6 of the European Social Survey, ESS Topline Result Series - Issue 5, available at: http://www.europeansocialsurvey.org/docs/findings/ESS6_toplines_issue_5_personal_and_social_wellbeing.pdf (accessed 2 June 2016).

Kawachi, I. (2016). Trust and public health, in Uslaner, R. (Ed.), Handbook on Social and Political Trust, New York: Oxford University Press.

Kenny, D. A \& McCoach, D. B. (2003). Effect of the Number of Variables on Measures of Fit in Structural Equation Modeling, Structural Equation Modeling, 10(3), pp. 333-351, doi: 10.1207/S15328007SEM1003_1 
Kish, L. (1994). Multi-population survey designs: Five types with seven shared aspects, International Statistical Review, 62(2), pp. 167-186.

Marsh, H. W., Hau, K. T. \& Wen Z. (2004). In search of golden rules: Comment on hypotheses-testing approaches to setting cutoff values for fit indexes and dangers in overgeneralizing Hu and Bentler's (1999) findings, Structural Equation Modeling, 11(3), pp. 320-341.

Michalopoulou, C. (2017). Likert scales require validation before application Another cautionary tale, BMS Bulletin de Méthodologie Sociologique, 134, pp. 5-23.

Michalopoulou, C. \& Symeonaki, M. (2017). Impoving Likert scale raw scores interpretability with k-means clustering, Bulletin de Méthodologie Sociologique, 135, pp. 101-109, doi: 10.1177/0759106317710863

Misztal, B. (2013). Trust in Modern Societies: The Search for the Bases of Social Order, Hoboken, NJ: John Wiley and Sons.

Muthén, L. K. \& Muthén, B. O. (1998 - 2017). Mplus user's guide (8th edition), Los Angeles, California: Muthén \& Muthén.

New Economics Foundation. (2009). National accounts of well-being: Bringing real wealth onto the balance sheet, London: NEF, available at: https://www. unicef.org/lac/National_Accounts_of_Well-being.pdf (accessed 5 May 2015)

Nooteboom, B. (2002). Trust: Forms, foundations, functions, failures and figures, Cheltenham: Edward Elgar.

Nunnally J. C. \& Bernstein I. H. (1994). Psychometric theory, New York: McGraw-Hill.

Panek, T. (2015). Subjective personal and social well-being in the European countries, in P. W. Sztabiński, H. Domański, F. Sztabiński (Eds), Hopes and anxieties in Europe, Frankfurt am Main: Peter Lang, pp. 27-52.

Putnam, D. (2000). Bowling Alone: The Collapse and Revival of American Community, New York: Simon \& Schuster.

Raykov, T. (2007). Reliability if deleted, not "alpha if deleted": Evaluation of scale reliability following component deletion, British Journal of Mathematical and Statistical Psychology, 60(2), pp. 201-216.

Rousseau, D. M., Sitkin, S. B., Burt, R. S. \& Camerer, C. (1998). Not so different after all: A cross-discipline view of trust, The Academy of Management Review, 23(3), pp. 393-404.

Schmitt, T. A. (2011). Current methodological considerations in exploratory and confirmatory factor analysis, Journal of Psychoeducational Assessment, 29(4), pp. 304-322.

Seligman, A. B. (2000). The problem of trust (2nd printing), Princeton: Princeton University Press. 
Tabachnick, B. G. \& Fidell, L. S. (2007). Using multivariate statistics, Upper Saddle River, New Jersey: Pearson Allyn \& Bacon.

Terwee, C. B., Bot, S. D. M., de Boer, M. R. van der Windt, D. A. W. M., Knol, D. L. Dekker, J., Bouter, L. M. \& de Vet, H. C. W. (2007). Quality criteria were proposed for measurement properties of health status questionnaires, Journal of Clinical Epidemiology, 60(1), pp. 34-42, doi: 10.1016/j.jclinepi.2006.03.012

The ESS Sampling Expert Panel. (2016). Sampling guidelines: Principles and implementation for the European Social Survey, London: ESS ERIC Headquarters, available at: http://www.europeansocialsurvey.org/ (accessed 2 June 2016)

Thompson, B. (2005). Exploratory and confirmatory factor analysis: Understanding concepts and applications, Washington, DC: American Psychological Association.

Uchida, Y., Takahashi, Y., \& Kawahara, K. (2014). Changes in hedonic and eudaimonic well-being after a severe nationwide disaster: The case of the Great East Japan Earthquake, Journal of Happiness Studies, 15(1), pp. 207-221.

Uslaner, E. M. (2002). The moral foundations of trust, Cambridge, UK: Cambridge University Press.

Uslaner, E. M. (Ed.) (2018). The Oxford handbook of social and political trust, Oxford, UK: Oxford University Press.

Warren, M. E. (Ed.) (1999). Democracy and trust, Cambridge, UK: Cambridge University Press.

Yamamura, E., Tsutsui, Y., Yamane, C., Yamane, S., \& Powdthavee, N. (2015). Trust and happiness: Comparative study before and after the Great East Japan Earthquake. Social Indicators Research, 123(3), pp. 919-935.

Yip, W., Subramanian, S. V., Mitchell, A. D., Lee, D. T., Wang, J., \& Kawachi, I. (2007). Does social capital enhance health and well- being? Evidence from rural China, Social Science \& Medicine, 64(1), pp. 35-49. 